NASA/TM—2009-215798

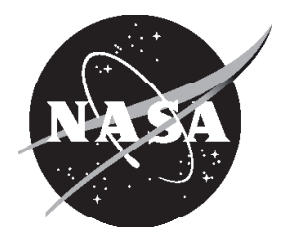

\title{
The Development of Wheels for the Lunar Roving Vehicle
}

Vivake Asnani, Damon Delap, and Colin Creager

Glenn Research Center, Cleveland, Ohio 


\section{NASA STI Program . . . in Profile}

Since its founding, NASA has been dedicated to the advancement of aeronautics and space science. The NASA Scientific and Technical Information (STI) program plays a key part in helping NASA maintain this important role.

The NASA STI Program operates under the auspices of the Agency Chief Information Officer. It collects, organizes, provides for archiving, and disseminates NASA's STI. The NASA STI program provides access to the NASA Aeronautics and Space Database and its public interface, the NASA Technical Reports Server, thus providing one of the largest collections of aeronautical and space science STI in the world. Results are published in both non-NASA channels and by NASA in the NASA STI Report Series, which includes the following report types:

- TECHNICAL PUBLICATION. Reports of completed research or a major significant phase of research that present the results of NASA programs and include extensive data or theoretical analysis. Includes compilations of significant scientific and technical data and information deemed to be of continuing reference value. NASA counterpart of peer-reviewed formal professional papers but has less stringent limitations on manuscript length and extent of graphic presentations.

- TECHNICAL MEMORANDUM. Scientific and technical findings that are preliminary or of specialized interest, e.g., quick release reports, working papers, and bibliographies that contain minimal annotation. Does not contain extensive analysis.

- CONTRACTOR REPORT. Scientific and technical findings by NASA-sponsored contractors and grantees.
- CONFERENCE PUBLICATION. Collected papers from scientific and technical conferences, symposia, seminars, or other meetings sponsored or cosponsored by NASA.

- SPECIAL PUBLICATION. Scientific, technical, or historical information from NASA programs, projects, and missions, often concerned with subjects having substantial public interest.

- TECHNICAL TRANSLATION. Englishlanguage translations of foreign scientific and technical material pertinent to NASA's mission.

Specialized services also include creating custom thesauri, building customized databases, organizing and publishing research results.

For more information about the NASA STI program, see the following:

- Access the NASA STI program home page at http://www.sti.nasa.gov

- E-mail your question via the Internet to help@ sti.nasa.gov

- Fax your question to the NASA STI Help Desk at $443-757-5803$

- Telephone the NASA STI Help Desk at 443-757-5802

- Write to: NASA Center for AeroSpace Information (CASI) 7115 Standard Drive Hanover, MD 21076-1320 
NASA/TM—2009-215798

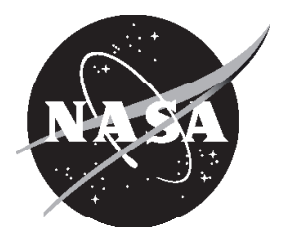

\section{The Development of Wheels for the Lunar Roving Vehicle}

Vivake Asnani, Damon Delap, and Colin Creager

Glenn Research Center, Cleveland, Ohio

National Aeronautics and

Space Administration

Glenn Research Center

Cleveland, Ohio 44135 


\section{Acknowledgments}

The authors would like to thank Professor Jo Wong, Dr. I. Robert Ehrlich, Dave Glemming, Jack Brown, Ron Creel, and Anthony Young for reviewing this manuscript. Special thanks to Ferenc Pavlics, Sam Romano, Don Friedman, and Nick Di Napoli for telling us this story and then fielding the barrage of questions.

Trade names and trademarks are used in this report for identification only. Their usage does not constitute an official endorsement, either expressed or implied, by the National Aeronautics and Space Administration.

Level of Review: This material has been technically reviewed by technical management.

Available from

NASA Center for Aerospace Information 7115 Standard Drive

Hanover, MD 21076-1320
National Technical Information Service 5285 Port Royal Road Springfield, VA 22161

Available electronically at http://gltrs.grc.nasa.gov 


\title{
The Development of Wheels for the Lunar Roving Vehicle
}

\author{
Vivake Asnani, Damon Delap, and Colin Creager \\ National Aeronautics and Space Administration \\ Glenn Research Center \\ Cleveland, Ohio 44135
}

\begin{abstract}
The Lunar Roving Vehicle (LRV) was developed for NASA's Apollo program so astronauts could cover a greater range on the lunar surface, carry more science instruments, and return more soil and rock samples than by foot. Because of the unique lunar environment, the creation of flexible wheels was the most challenging and time consuming aspect of the LRV development. Wheels developed for previous lunar systems were not sufficient for use with this manned vehicle; therefore, several new designs were created and tested. Based on criteria set by NASA, the choices were narrowed down to two, the wire mesh wheel developed by General Motors (GM), and the hoop spring wheel developed by the Bendix Corporation. Each of these underwent intensive mechanical, material, and terramechanical analyses, and in the end, the wire mesh wheel was chosen for the LRV. Though the wire mesh wheel was determined to be the best choice for its particular application, it may be insufficient towards achieving the objectives of future lunar missions that could require higher tractive capability, increased weight capacity, or extended life. Therefore lessons learned from the original LRV wheel development and suggestions for future Moon wheel projects are offered.
\end{abstract}

\subsection{Introduction: Wheels on the Moon}

In the early 1970s, three types of wheeled vehicles were used on the lunar surface. The missions for these vehicles were completely different, and accordingly they had dissimilar wheel designs. For comparison, Figure 1 lists the characteristics of these vehicles (Fig. 1(a)) and their wheels (Fig. 1(b)). The first was the Russian made robotic rover called Lunokhod ('Moon Walker' in English). This was an $800 \mathrm{~kg}$ remotely controlled vehicle that traveled at a maximum speed of $2 \mathrm{~km} / \mathrm{hr}$. Lunokhod had eight rigid-rim wire mesh wheels, with bicycle-type spokes. The second vehicle, which was American made, was the Modularized Equipment Transporter (MET), a two-wheeled unpowered cart used to carry equipment and samples collected by the astronauts on Apollo 14. The MET was about $75 \mathrm{~kg}$ when loaded, and was pulled at speeds up to $4 \mathrm{~km} / \mathrm{hr}$. Its wheels were made of smooth rubber, and were supported by nitrogen filled inner-tubes. To make it easier to pull the cart through soft lunar soil and over rocks, the MET wheels were designed to be fairly compliant. The last vehicle to visit the Moon was the Lunar Roving Vehicle (LRV). This was a manned vehicle that could sustain a maximum speed of about $16 \mathrm{~km} / \mathrm{hr}$ and had a total mass of approximately $700 \mathrm{~kg}$ when fully loaded (unloaded mass was $210 \mathrm{~kg}$ ). The LRV had a $4 \times 4$ configuration ( 4 wheels, all driven) using large flexible wire mesh wheels with stiff inner frames to prevent over-deflection. Thin tread strips were attached to the carcass to enhance floatation in soft lunar soil yet still allow the carcass to deflect. Although each of these wheel designs were distinctly different, they all adequately served their respective functions.

Unfortunately, very little of the lunar wheel technology was transferred to the private sector. This is because there are no Earth applications with similar mission and environmental constraints. Some of the special considerations for lunar wheel development are:

- Restricted transport mass and volume.

- Potential variation in temperature from approximately 40 to $400 \mathrm{~K}\left(-230\right.$ to $\left.130{ }^{\circ} \mathrm{C}\right)$.

- Exposure to solar radiation without atmospheric protection.

- Rolling and sliding contact with un-weathered regolith and dust particles. 
- Operation in a hard vacuum.

- Operation in a low gravity field (1/6th Earth's gravity).

With the new initiative to inhabit the Moon, wheels will be needed for exploration, construction, and other surface operations. The designers will need to learn how to satisfy the unique environmental constraints and meet the transportation requirements of a given mission. To facilitate this effort, the development process of the LRV wheel was studied and is reported in this article. From this account, lessons learned are documented and suggestions for future work are offered.

\subsection{Development of the LRV Wheel}

The contract to develop the LRV was awarded to The Boeing Company in October of 1969 and the first flight vehicle was delivered to NASA in March of 1971. General Motors (GM) was the major subcontractor for this project. Throughout the 1960s GM's Defense Research Laboratories (GM DRL) invested time and resources to develop a wheel that would work for such a mission. Based on a detailed review of the literature, as well as interviews with several original GM DRL team members (Pavlics $2007 \mathrm{a} / \mathrm{b}$ ), a retrospective account of this development is conveyed below.

\subsection{Genesis of the Design Concept}

SLRV (1963 to 1964): In 1963, GM DRL teamed with Goodyear Tire \& Rubber Company (Goodyear) to develop several prototype wheels for the Surveyor Lunar Roving Vehicle (SLRV). This was a small teleoperated rover that was intended to scout the lunar surface before the Apollo program. A few of these wheel concepts are shown in Figure 2. The commonality between designs was the carcass configuration, which was formed with wire and resembled the cord structure of a bias tire. At the intersections, the wires were looped to maintain their spacing and still allow for pantographing (pivoting action that occurs between tire-cords when the carcass is deformed). The wire frame wheels were well suited for the lunar application in several ways. Primarily, they were compatible with the lunar environment. The compliance of these wheels could be tuned by varying wire thickness, bias angle, and number of wires. They could be designed to deform significantly, thus providing high tractive capability, even under the relatively low weight of lunar vehicles in 1/6th gravity. In addition, the wire frame wheels could be made very light by only partially covering the carcass (e.g., Fig. 2(a) to (c)). As such, several coverage schemes were tried to balance the weight reduction and tractive performance. The partially covered configuration also prevented clogging between tread pieces, since soil was free to flow in and out of the carcass. These wheels solved several of the fundamental problems associated with lunar wheel design; however, they had low fatigue life due to stress concentrations at the looped intersections. The SLRV program was eventually cancelled because of concern that it might interfere with the Apollo missions.

MOLAB (1964 to 1965): NASA next sponsored the study of a Mobile Lunar Laboratory (MOLAB). This was a large pressurized vehicle to be used for long range exploration after the Apollo program. GM DRL and Goodyear again worked together and made a larger wire frame wheel with higher load capacity. However, they found that the wheel design could not easily be scaled to accommodate a higher load. For example, increasing the wire diameter elevated the stresses at the looped intersections, while increasing the number of wires made the wheels difficult to manufacture by hand. Working within these limitations, the prototype shown in Figure 3 was made; however, the wheel carcass was unable to support the vehicle weight. To fix this problem, a method to weave the carcass was developed at GM DRL using the process illustrated by Figure 4. As shown, the wires were precrimped at fixed intervals. In this fashion, they held their position in the carcass without excessive stress. Additionally, the manufacturing process enabled a much tighter spacing between wires.

MTA (1966 to 1967): NASA sponsored GM DRL to build a Mobility Test Article (MTA) as a way to simulate the mobility performance of the MOLAB rover. This was essentially a $6 \times 6$ chassis that had the 
same weight on Earth as MOLAB would in lunar gravity. The vehicle had large $(\sim 152 \mathrm{~cm})$ wire mesh wheels and was tested on hard surfaces at the Army's Aberdeen Proving Ground, and then on desert terrain at their Yuma Proving Ground (Smith 1967, Northon 1967). The mesh wheels worked fine at Aberdeen but did not survive testing over the rocky terrain at Yuma. High speed impacts broke wires, and the mesh carcass was permanently dented while crawling through a boulder field. After this, rubber inner tubes were used to prevent overdeflection of the carcass during testing. In later versions of the wheels, the rubber inner-tube was replaced by a titanium inner-frame, as shown in Figure 5. Tread strips were also added to the carcass for protection. The tread pieces were arranged in a chevron pattern, which helped provide side-traction and prevent the wheel from drifting.

To enhance the forward thrust capacity, large spaces were used between the tread. The inspiration for this came from the so-called 'spaced link track' that was investigated in the early 1960s by Dr. M.G. Bekker (Bekker 1960). At the time, there were several conflicting hypotheses about the trafficability of the lunar surface. It wasn't clear if the terrain was strong enough to support a wheeled vehicle; therefore alternate running gear types such as screws and tracks were investigated (Bekker 1962, Bekker 1963). Figure 6 shows three small scale prototype lunar vehicles that were studied. The spaced link track is shown at the right of the picture. In principle, the spacing between its cleats created a longer shearing surface that extended deeper into the terrain and thus developed more traction than a continuous footing. The phenomenon is illustrated in Figure 7. Here cleats 1 and 2 were loaded and translated in sand, while filmed from behind a glass wall. The camera was moved alongside so the sand grains that traveled along with the cleats stayed in focus while the stationary ground underneath was distorted. Soil was sheared off and carried between cleats 1 and 2, causing shear displacement to occur, and thus shear strength to develop along surface $a$ to $b$. In the open space behind cleat 2 , a much longer shearing surface, $b$ to $c$, was produced, yielding greater thrust development.

The wire mesh wheel concept that incorporated all of the technology developed at GM DRL up to 1967 is shown in Figure 5. This wheel was the subject of extensive evaluation and testing before finally being configured for the LRV.

\subsection{Comparative Evaluation}

LSSM (1966 to 1967): After MOLAB and GM DRL was subcontracted by Boeing to investigate the Lunar Scientific Surveyor Module (LSSM) for NASA. This was a two-astronaut unpressurized rover concept. To determine the relative merit of the wire mesh design, it was analyzed along with other candidate lunar wheels.

\subsubsection{Concept Selection}

In all, eight wheels were selected for the preliminary analysis, as shown by the matrix in Figure 8. Most of the wheels evaluated were those considered seriously for lunar exploration by major companies. Rigid rim and pneumatic wheels were also included in the analysis, because they were commonly used on Earth.

To build and test all eight wheels was impractical, so a combination of analytical techniques, simple experiments, and engineering judgment was used. For example, soft ground performance was estimated by assessing the terrain contact geometry and then calculating thrust and motion resistance using the Bekker method (Bekker 1969). Results showed that large ground contact length was key to lowering motion resistance and increasing thrust. The spacecraft volume limited running gear dimensions, so a flexible wheel carcass was considered paramount to achieving the long footprint.

In each of the categories, a score between 0 and 10 was assigned. Additionally, each criterion was designated an importance weighting factor, according to a manned mission scenario. The total score was calculated for each wheel, using a weighted average of the category scores. Though pneumatic wheels are most commonly used on Earth, they were disregarded after receiving a null score in the environmental compatibility category. This was because of the risk associated with deflation in the airless lunar environment, as well as potential rubber degradation due to solar radiation (Bekker 1985). The other 
design with terrestrial heritage, the rigid rim wheel, was also disregarded because of its null score in ride comfort. Overall, the wire mesh wheel was rated highest, while having no prohibitive low scores. It was also rated best in weight, ride comfort, and obstacle performance. Second best was the hoop spring wheel, which was tied for the highest soft ground performance rating with the spiral spring wheel and hubless design. These two designs, the wire mesh and the hoop spring, were selected for further development and experimental analysis.

\subsubsection{Developmental Program}

To characterize and further develop the wire mesh and hoop spring wheel concepts, GM DRL used a design-test-redesign-retest approach. The developmental program is outlined in Table 1 (GM 1967). Initial versions of both wheels were built according to the LSSM mission requirements shown in Table 2. These wheels were put through mobility and mechanical tests to determine their limitations. Concurrently, tensile strength, fatigue, and vacuum welding tests were done on several candidate materials. From the wheel performance and material evaluation data, design changes were made. The improved wheels were reevaluated in the mobility and mechanical test rigs to determine their relative performance. Finally, a mission simulation was performed under lunar thermal-vacuum conditions using a wheel dynamometer. At the end of both phases of testing, final recommendations were made for further improvements to both wheels designs and technical drawings were produced. The methods and results from this program are summarized below.

\subsubsection{Initial Wheel Designs}

The initial wire mesh (MESH-1) and hoop spring (HOOP-1) designs were scaled versions of the MOLAB wheels developed by GM DRL and the Bendix Corporation, respectively (Boeing 1965, Bendix 1965). The prototypes were built in-house to gain an understanding of the manufacturing processes. Figure 9 shows pictures of these wheels.

The MESH-1 wheel had a woven spring-steel wire mesh carcass with tread strips, a titanium inner frame, and an aluminum hub and wheel disc. Its carcass was designed to support the load of the vehicle under nominal conditions, and the inner frame served as a secondary spring and deflection boundary for the mesh during impact loading. The mesh structure distributed the load throughout much of the carcass by globally deforming. The tread pieces provided additional contact area for floatation, and were indented to developed traction through general shear failure (e.g., Fig. 7, surface b to c).

The HOOP-1 wheel consisted of a titanium outer band, hoop spring elements, and a rigid aluminum hub with spokes. Under nominal loading, the outer band and hoop springs carried the load locally. Other than the rigid aluminum hub, no deflection limiting devices were incorporated. The contact patch of the wheel was relatively large and uniform, which facilitated floatation. No tread was used and so the traction depended on friction at the metal to soil interface. If the friction was high enough to mobilize the soil, then traction would develop through local shear failure (e.g., Fig. 7, surface a to b).

Mobility Testing: Initial testing was done to benchmark soft soil performance. Each wheel was subjected to drawbar pull, rolling resistance, and steering resistance testing. All of these tests were done at 100,150 , and 200 percent of the nominal design load. Two types of soil were used; the first was a course, dry sand, and the second was a very soft, fluffy material called Perlite. These materials were used to cover the range of surface conditions estimated by NASA in their lunar surface model (Mason 1964), which was based on the Ranger mission photographical data.

The resistance in sand for both wheels was very close at the design load. However, with increasing load, the rolling resistance of $M E S H-1$ grew faster than for the HOOP-1. This trend was more apparent in the softer Perlite. There were no significant differences in steering resistance between the two wheels at nominal loading. Finally, under all conditions, MESH-1 developed more drawbar pull than HOOP-1.

Because of the fact that there was no significant difference in the rolling resistance of the wheels, the higher drawbar pull developed by $M E S H-1$ was attributed to greater thrust development. It was postulated that $H O O P-1$ could not develop as much thrust as $M E S H-1$, because the friction between the metal and soil was too low, and the wheel slipped at the interface. Similarities in the steering resistance results were 
explained by examining the geometric characteristics of the wheels. The sharp edges of $H O O P-1$ cut through the soil, while $M E S H-1$ had a rounded contour that helped mitigate soil buildup in the travel path.

Mechanical Testing: Several tests were done to characterize the mechanics of the wheels and find their structural limitations. Load-deflection tests were performed in the vertical, lateral, and longitudinal directions, while recording the contact geometry of the wheels. Following this, a dynamic checkout was done to observe the wheel response at operational speeds and torques. Impact endurance testing was then performed with single and random obstacles. Finally, the wheels were endurance tested on a smooth surface for up to 75,000 revolutions.

Several limitations of the hoop spring wheel were revealed during this testing phase. While dynamically testing HOOP-1, significant vibration, or "flutter", was observed in the outer rim at critical speeds. Additionally, it was unable to develop high torque on the treadmill surface. During the single obstacle tests, the hoop springs became overstressed and failed. As such, an identical hoop spring wheel $(H O O P-2)$ was fabricated to continue the mechanical testing. In the endurance tests, the hoop springs in HOOP-2 began to fail at about 18,000 cycles and the test was terminated at 28,000 cycles when more than half of the hoops had failed. As such, no further mechanical testing on the initial hoop spring design was performed. It was observed that the wheel failures seemed to initiate at the hoop spring attachment points. At these locations, a slight reverse bending occurred and stress concentrations formed around the riveting holes.

Wheel MESH-1 was relatively stable during the dynamic checkout test. However, during the endurance test the wires in MESH-1 began to break at 19,000 cycles, and more than 10 percent had broken by 27,000 cycles. At this time, it was observed that most of the wires broke in line with the ends of the tread strips. It became clear that the tread strips did not allow the tread and the mesh to move independently during the deflection of the wheel; thus, the wires were being overstressed. To continue the testing, a refurbished mesh wheel $(\mathrm{MESH}-2)$ was built. The tread strips were segmented at the riveting points to allow them to pivot, and as a result, alleviate the added stress to the wires. The new wire mesh wheel successfully completed the endurance test and the random obstacle test without any failures.

\subsubsection{Materials}

Material level testing was done concurrently with the initial mobility and mechanical evaluation. The purpose was to assess eight candidate materials for the wire mesh wheel carcass and to verify the adequacy of the titanium alloy used for the spring elements and outer band in the hoop spring wheel. Three samples of each material were subjected to tensile strength, fatigue, and vacuum welding tests.

Results from the tensile tests verified the published values for yield and ultimate strength. Five of the eight wire materials endured representative bending stresses for over 300,000 cycles, or three times the required wheel life. However, of all the wire types tested, standard music spring wire was the least prone to vacuum welding. It was also observed that the effects of vacuum welding did not degrade the performance or fatigue life of the music spring wire. The titanium material being evaluated for the hoop spring wheel also lasted 300,000+ stress cycles, and there were no significant vacuum welding effects.

\subsubsection{Improved Wheel Designs}

Improved hoop spring $(H O O P-3)$ and wire mesh $(M E S H-3)$ wheels were built according to recommended changes from initial testing, and had the following features:

\section{HOOP-3}

1. The titanium alloy continued to be used for the hoop springs and the outer band.

2. To lower operating stresses, the hoop springs were made thinner, they were elliptically preformed, and twice as many were used.

3. The outer surfaces of the hoop springs were shot peened to improve fatigue life.

4. A bump stop was added to limit the deflection of the hoop springs.

5. To increase the thrust development, two alternate tread configurations were tried, a sand paperlike grit and $0.6 \mathrm{~cm}$ high aluminum grousers. 


\section{MESH-3}

1. Standard music spring wire was used for construction of the mesh carcass.

2. Segmented tread pieces continued to be used with additional tread pieces added to help with floatation.

Mobility Testing: The mobility test procedures were repeated on HOOP-3 and MESH-3, except they were not tested in the Perlite material. At this point, additional observations from the Surveyor missions (e.g., see Vaughan 1967) indicated that only a thin layer of the soft, fluffy material covered the lunar surface. It was decided that this layer would not affect vehicle mobility.

For the most part, rolling resistance tests for both wheel types showed no significant differences from the initial testing. However, with the addition of the grit to the tread, the drawbar performance of $H O O P-3$ was significantly improved over $H O O P-2$. The addition of grousers yielded no further benefit, except at high loads and high wheel slip. With the additional tread pieces, the drawbar pull developed by $M E S H-3$ was slightly higher than MESH-2, but shy of that produced by either improved hoop spring wheel design.

Since the motion resistance of the $M E S H-3$ and $H O O P-3$ did not change, their improved drawbar performances were attributed to increases in thrust. The increase in thrust for $M E S H-3$ was credited to the larger tread surface taking advantage of a small amount of cohesion in the sand. This cohesion was assumed to be a result of the ambient moisture conditions and could not be relied on for propulsion in the lunar environment. The significant increase in thrust for $H O O P-3$ implied that the wheel was no longer slipping at the wheel/soil interface. Finally, it was postulated that $H O O P-3$ generated more drawbar pull than $M E S H-3$ because it had a larger contact patch and could take greater advantage of the cohesive terrain strength.

Mechanical Testing: The mechanical testing done during the initial testing phase was repeated on HOOP-3 and MESH-3. HOOP-3 reached 55,000 cycles with 10 percent of the spring elements breaking. Again, most of these breaks initiated where the hoop springs were fastened. $M E S H-3$ reached 85,000 cycles with 10 percent of the wire breaking. However, the wire breaks occurred where the single-obstacle repeatedly struck the wheel. This round of testing indicated that wheel lives were extended by the design changes, although the endurance of $H O O P-3$ was still limited by stress concentrations at the loop attachment points.

Simulation: Final tests were performed to evaluate how the wheels would operate under simulated lunar environmental conditions. For this purpose, two new wheels (HOOP-4 and MESH-4) were constructed, which were identical to $H O O P-3$ and $M E S H-3$. A special wheel dynamometer, shown in Figure 10, was constructed to be used inside a thermal-vacuum chamber. The wheels were operated under nominal loading on a smooth surface (steady-state mode) and over obstacles (dynamic mode) with the duty cycles of wheel torque and speed controlled to simulate the LSSM mission profile.

The cycles accumulated in the various modes of testing are outlined in Table 3. Although the testing cycles were not equivalent, both wheels were run until failure in the dynamic thermal-vacuum mode. The failure modes were the same as in previous tests; the wires in the mesh wheel failed in-line with an obstacle, while the hoop spring wheel failure originated at the spring hoop attachment points. As in the previous tests, the wire mesh wheel lasted quite a bit longer.

Conclusions of Testing: From the test program with the improved wheel designs, the following conclusions were drawn:

\section{Hoop Spring Wheel}

1. This design suffered from excessive vibration, or flutter, at critical speeds.

2. The addition of grit effectively increased the wheel-terrain friction and enhanced the thrust capability.

3. The bump stop successfully prevented overdeflection. 
4. The modified hoop springs resulted in sufficient fatigue life for smooth surfaces.

5. Reverse bending of the hoop springs still occurred when rolling over sharp obstacles. As a result, fatigue was inadequate for the LSSM specifications.

\section{Wire Mesh Wheel}

1. Soft soil performance of the improved wire mesh wheel was slightly inferior to the improved hoop spring wheel. However, the difference was attributed to cohesion in the sand from the ambient moisture, which could not be relied on to aid propulsion on the Moon. Thus, soft soil performance was deemed equivalent to the hoop spring wheel.

2. Obstacle course endurance testing revealed that this wheel would not quite satisfy the 100,000 cycle LSSM requirement for life. This was attributed to repeated striking of the same locations on the wheel. The life during an actual mission would be greater due to the randomness of natural obstacles.

3. The wheel life could be extended significantly by lowering the wire stresses. It was recommended that smaller diameter wires be used in future wheel designs. Additionally, it was suggested that the tread strips be made wider to protect the sidewalls from impact damage.

\subsection{Configuration for the LRV Missions}

$\boldsymbol{L R V}$ (1969 to 1971): In July of 1969, NASA released the request for proposals (RFP) to develop the LRV. This document specified the operational requirements, as well as the mass and volume limitations imposed by the landing spacecraft. As the mobility system subcontractor to Boeing, GM DRL assessed the vehicle specifications and translated them into wheel requirements. Results from the experimental development program indicated that the wire mesh wheel design was better suited for this mission than the hoop spring wheel. Most notably, the wire mesh wheel would offer superior stability, ride comfort, and had a better chance of meeting the life requirements than the hoop spring wheel. As such, the wire mesh design was selected and configured for the LRV mission. The configuration process is not exactly known, but has been inferred from the literature (GM 1970a/b, GM 1971) and technical discussion with former LRV team members (Pavlics 2007a/b). The presumed configuration process based on NASA mobility requirements for the LRV is outlined in Table 4. The terramechanics aspect of the wheel design and testing is described in detail below. After the LRV wheel design was finalized (Fig. 11), it was handed over to NASA for mobility subsystem space qualification. More information on the LRV subsystems can be found in (Young 2007).

\subsection{Terramechanics Configuration}

The most challenging factor in the wheel configuration was the vehicle requirement to climb a $25^{\circ}$ slope for a $0.5 \mathrm{~km}$ distance. The wheel needed to generate enough thrust to overcome its internal resistance, the gravitation resistance, and the resistance due to terrain compaction. As mentioned previously, Bekker's method of analysis (Bekker 1969) showed that the most influential design parameter was the ground contact length. However, since the LRV wheel geometry was maximized for the given spacecraft volume, the contact could only be lengthened by increasing the carcass deflection. The equations reported in (Pavlics 1966) were used to relate the nominal wheel deformation to climbing performance. The primary assumption was that the ground contact was rectangular, with uniform pressure distribution. Clearly, this was not the case for the complex geometry of the LRV wheel; nevertheless, the method provided an approximate solution for studying tractive performance parametrically.

Figure 12 is an example design plot generated retrospectively using the lunar terrain parameters recommended in the LRV RFP (Table 5), in conjunction with the wheel geometry (GM 1971) and empirically determined internal loss characteristics (Pavlics 1966). Here, the $25^{\circ}$ climbing condition is used and mobility forces are shown for 20 percent wheel slip. As expected, the thrust is increased and motion resistance lowered with increased nominal deflection. The plot indicates that thrust equals motion resistance, and thus the vehicle should be capable of traversing the $25^{\circ}$ slope if the wheel carcass deflects 
$3 \mathrm{~cm}$ nominally. Additional deflection would then provide a margin of safety to account for stochastic variation in terrain strength. On the other hand, additional deflection would amplify the nominal wire stresses and cause the bump-stop to engage more often. Considering these tradeoffs, GM DRL designed the wheel carcass to deflect about $4.5 \mathrm{~cm}$ under the nominal load.

Early studies at GM DRL showed that tread spacing had a significant influence on the terrain failure pattern, and thus tractive performance (Fig. 7). The phenomenon was not well understood and so several wire mesh wheels with different tread spacing, and hence different total tread coverage (ranging from 0 to 100 percent coverage), were built for comparative evaluation at the U.S. Army Waterways Experiment Station (WES) (Freitag 1972, Green 1971a,b/Melzer 1971). Wheel dynamometer testing was done on a lunar soil simulant (LSS), which emulated the mineralogy and particle distribution of lunar soil samples collected on the Apollo 11 and 12 missions. This simulant was prepared to low, medium, and high density terrain conditions (LSS1, LSS2, LSS3, respectively), and a low density condition with a small amount of water added (LSS4). These preparations covered the range of frictional and cohesive terrain strength specified by NASA in the RFP (Costes 1972). Based on a thorough analysis of single wheel drawbar pull and associated power consumption data, the wheel with 50 percent tread coverage was determined to be the optimum design. As an example, data from LSS1, the loosest terrain condition, is summarized in Table 6. The data shows that the 50 percent covered wheel consumes the minimum power at the self propelled point (without external resistance) and also has the highest drawbar pull capability at 20 percent slip. Note that the 20 percent slip condition was empirically determined to be the point where the wheel generated the maximum drawbar pull without excessive power consumption.

The slope climbing ability of the LRV was also determined on the basis of the single-wheel drawbar pull results, using an empirical equation that correlated these data with measured vehicle climbing performance (Freitag 1970/1972). Like in the drawbar pull evaluation, the 20 percent slip point was used as the maximum value in assessing gradeability. A curve fit of about 500 slope versus slip data points encompassing all terrain conditions (LSS1 through LSS4) was generated retrospectively and plotted in Figure 13. Data ranges corresponding to one, two, and three standard deviations from the mean slope climbing performance are also shown. The slip required to achieve the $25^{\circ}$ slope climbing requirement for each range are summarized in Table 7. On average 59.5 percent slip is required; however, 72.0, 79.5, and 84.5 percent slip are associated with one, two, and three standard deviations of the data, respectively. This implies that the wheel travel while traversing $0.5 \mathrm{~km}$ on a $25^{\circ}$ slope could actually be up to $3.2 \mathrm{~km}$, or so. GM DRL personnel performed a similar analysis of the data and were aware that the LRV would operate at high slip if a similar slope was encountered. They performed a thermal analysis and verified that the drive motors could sustain the required torque for the extra cycles needed. Additionally, the energy consumption associated with this traverse was calculated to be only a small fraction of the vehicle's reserve. Thus, it was considered acceptable to operate the vehicle at high slip in order to meet the climbing requirement. A detailed review of the LRV performance on the Moon, including the postmission report by the Apollo $15 \mathrm{crew}$, is provided in (Costes 1972). Slopes of no more than $12^{\circ}$ were encountered during the mission, and the crew indicated that tractive performance of the wire mesh wheels was excellent.

\subsection{Summary, Lessons Learned, and Suggestions for Future Work}

\subsection{Summary}

Lunar wheel design poses a different challenge than terrestrial wheel design because of the unique environmental conditions and stringent mass/volume limitations. Each of the three wheel types used on the Moon were distinctly different, but appropriate for their respective missions. The development of the wire mesh wheel for the LRV was studied in detail to understand the most challenging factors and provide guidance for future designers.

The basic wire mesh wheel technology was developed during the years 1963 to 1967 . This wheel had a solid hub with a woven wire carcass, and a skeleton-like inner frame that prevented the carcass from 
over deflecting. The carcass was partially covered by thin tread strips that enabled floatation over soft soil, and, in theory, developed propulsive force through generalized shear failure. All of the fundamental design features (e.g., mesh carcass, inner frame, tread strips, etc.) emerged as solutions to failures sustained while testing various prototypes.

From 1966 to 1967 the wire mesh wheel was compared to other candidate designs with regard to a manned lunar mission scenario. For the given criteria, the wire mesh and the 'hoop spring' wheels were judged to be the most suitable designs and were further developed. The hoop spring wheel had a spoked hub and a one-piece metal rim supported by flexible metal hoops. Both wheel types were subjected to a design-test-redesign-retest program, in order to compare their performances and make improvements. This program included material, mechanical, and in-soil mobility tests. The improved wheel designs were then endurance tested under simulated lunar environmental conditions.

The wire mesh wheel was determined to be most appropriate for the LRV mission because it offered superior stability, ride comfort, and longer life. Configuration and verification of the wheel to meet the LRV mission requirements was mostly done in 17 months, from October 1969 to March 1971. Since the procedure was not explicitly documented, the process was estimated with some assistance from former GM DRL employees. The most notable aspect was the selection of the wheel geometry and stiffness to climb a $25^{\circ}$ slope on the Moon for $0.5 \mathrm{~km}$. The Bekker method of terramechanical analysis, along with estimates of the lunar terrain strength properties, was used to relate the wheel's ground contact geometry to its propulsive capacity. This method was used to select the nominal carcass deflection with regard to the climbing capability. Subsequently, the tread spacing was optimized using single wheel tests in lunar soil simulant. The test results indicated that the analysis overestimated the wheel's performance, and that the wheel would need to slip significantly in order to generate enough traction to traverse the required slope; however, the power reserves were sufficient enough to allow this.

\subsection{Lessons Learned}

This article has revealed several lessons pertaining to lunar wheel design.

\section{Lesson 1: Lunar Wheel Designs are Mission Dependant}

The three wheel designs used on the Moon were entirely different and were developed specifically to meet their respective mission requirements. The rubber-pneumatic tire does not have the same utility on the Moon, because the material and air-spring properties change in that environment. Furthermore, the possibility of a 'flat tire' is not acceptable for a manned vehicle. A 'flat tire' would be a form of singlepoint failure and would immediately render the vehicle immobile. This would not only be costly to a mission, but could be very dangerous for astronauts if the puncture were to cause a tire explosion in zero atmospheric pressure. Various configurations of airless, metal wheels have been proposed (Fig. 8), which tend to trade-off performance and reliability. As such, it is important to clearly understand the application and associated requirements when selecting a lunar wheel concept.

\section{Lesson 2: Considerable Lead Time is Required to Develop a New Lunar Wheel Concept}

The development of a wheel that operates in the unique environment of the Moon could take most of a decade, as in the case of the LRV wheel. The majority of that time was spent updating the design concept through iterative building and testing. Once the basic design was established, it was then reconfigured for the LRV mission in a relatively short time.

\section{Lesson 3: Field Testing is Paramount to Understanding Lunar Wheel Performance}

From 1960 to 1967, prototype lunar wheels were built and tested by GM DRL for NASA mission feasibility studies (SLRV, MOLAB, MTA, and LSSM). All of the critical features in the final LRV wheel design (e.g., wire mesh carcass, inner frame, tread strips, etc.) emerged as solutions to failures observed while testing these prototypes. Because it is very difficult to simulate the complex interaction between a 
wheel and its environment, field testing under realistic terrain conditions is essential to understanding the strengths and weaknesses of a design.

\section{Lesson 4: The Most Critical and Most Difficult Aspect of Lunar Wheel Design is the Flexible Carcass}

The lunar wheel carcass is critical, because its ground contact geometry and pressure distribution control the tractive performance of the vehicle. Results from a simple analysis using the Bekker method are shown in Figure 12, which indicate that wheel deformation significantly benefits slope climbing ability. However, the range of temperatures on the Moon makes typical elastomeric materials unusable. The alternative is to create a metal mechanism (such as the wire mesh) that deforms and/or repositions under load. Such a mechanism must endure repeated cycling, persistent impacts, and be capable of withstanding sliding contact with unweathered regolith. The wire mesh structure served this purpose on the LRV wheel, but was the most formidable challenge in the design.

\subsection{Suggestions for Future Work}

The following recommendations are intended to help focus subsequent lunar wheel technology development.

\section{Recommendation 1: Establish the Wheel Requirements for New Missions}

Any technology development effort should start by establishing the wheel requirements associated with the target missions. This is very important, given the specificity of lunar wheel designs. The basic information needed is as follows:

1. Level of redundancy

2. Thermal and radiation exposure

3. Number of wheel cycles

4. Work requirements versus the terrain conditions

5. Timeline for development

With these data, lunar wheel concepts may be evaluated and compared to determine their applicability to each mission scenario.

\section{Recommendation 2: Benchmark Terramechanics Models for Lunar Wheel Evaluation}

The work that a wheel can perform is dependent on its interaction with the terrain. During the Apollo program, the Bekker method was used to predict the terramechanics of candidate designs. However, soil bin experiments performed at WES with the final LRV wheel showed that the Bekker method over predicted performance. This technology was very young at the time, and since then many advancements have been made. However, most modern terramechanics models are empirical and have not been evaluated for the lunar case. The main discrepancy is that lunar wheels apply relatively low ground pressure in 1/6th gravity. Modern methods in terramechanics should therefore be benchmarked against the data available from the WES soil bin experiments in order to determine their applicability.

\section{Recommendation 3: Develop Lunar-Specific Wheel-Terrain Testing Procedures}

Several different wheel performance and endurance tests were performed during the development process of the LRV wheel. Some tests, such as drawbar pull, provided in-situ performance information. Other tests, such as the treadmill obstacle endurance, enabled comparative evaluation of wheel concepts, but did not provide a reliable estimate of life, for example. The suite of lunar wheel tests should therefore be examined in order to understand their utility and relationship to performance on the Moon. Eventually, lunar wheel testing procedures should be established for both comparative evaluation and mission planning. 


\section{Recommendation 4: Determine the Limitations and Reconfigureability of the Wire Mesh Wheel}

Assuming wheel requirements and evaluation methods are established, the analysis of candidate lunar wheel types should proceed in order of technology readiness level (TRL). Clearly the wire-mesh LRV wheel should be examined first. Quite a few of the LRV wheel limitations are already known from past testing. For example, its slope climbing capabilities on lunar soil simulant has already been studied and is summarized by Figure 13. Additionally, the design has been qualified for a manned mission of up to $120 \mathrm{~km}$, with a maximum speed of $16 \mathrm{~km} / \mathrm{hr}$. The power requirements and pull capabilities of the LRV wheel have also been thoroughly characterized for a range of lunar terrain strength. Most of the remaining questions pertain to the extension of this design to alternative mission scenarios. Example in its current configuration, how much further than $120 \mathrm{~km}$ can the LRV wheel be used? How can the wire mesh design be scaled to different geometries and for various loads? How is the soft-soil performance affected by parametric changes?

To establish its endurance limit, replicate LRV wheels should be made and tested. However, since it's important to understand the scaling and performance relationships, a wheel-terrain model must also be developed. From the design point of view, the following two relationships would need to be simulated. (1) the carcass deformation, as a function of the wire diameter and number of wires; and (2) the terrain deformation pattern, as a function of the ground pressure distribution. With such a model, the wire-mesh carcass and tread pattern could be reconfigured for alternative load, geometry, or work requirements. If the LRV wheel design cannot be reconfigured to meet specific needs, then design modifications should be considered.

\section{Recommendation 5: Evaluate Other Wheel Designs in Order of TRL}

In the case that the wire mesh wheel concept does not cover the needs for future lunar exploration, then other high TRL designs should be examined. The Lunokhod and MET wheels are options, but according to the assessment by GM DRL, they would not be usable for manned missions, because of poor ride quality and lack of redundancy, respectively. New, as well as current, designs should be considered and evaluated. The results of the trade study at GM DRL (Fig. 8) should be used as a reference to determine which concepts to examine, with regard to the new criteria set forth.

\section{References}

Bekker M.G. Off-the-road Locomotion: Research and development in terramechanics. University of Michigan Press; March 1960.

Bekker M.G. Land locomotion on the surface of planets, ARS Journal; 1962.

Bekker M.G. Mechanics of locomotion and lunar surface vehicle concepts, Defense Research Laboratories at General Motors Corp., paper no. 632K. In: Automotive Engineering Congress; January 1963.

Bekker M.G. Introduction to terrain-vehicle systems, The University of Michigan Press; 1969.

Bekker M.G. The development of a Moon rover. Journal of the British Interplanetary Society, 38: 537-543; 1985.

Bendix. ALSS payloads (MOLAB), final report, volume III, Local Scientific Survey Module conceptual design, document no. BSR-1119; June 1965.

Boeing. ALSS payloads (MOLAB), detailed technical report, mobility systems - vehicular, document no. D2-83203-1; June 1965.

Coleman H.W., et al. Experimentation and Uncertainty Analysis for Engineers. John Wiley \& Sons, Inc., pgs. $40-52 ; 1989$.

Costes, N.C. et al. Mobility performance of the Lunar Roving Vehicle: Terrestrial studies: Apollo 15 results. NASA TR-R-401; 1972.

Freitag D.R., et al. Performance evaluation of wheels for lunar vehicles. U.S. Army Waterways Experiment Station technical report no. M-70-2; 1970. 
Freitag D.R., et al. Wheels for lunar vehicles, Journal of Terramechanics, 8(3): 89-105; 1972.

Green A.J., et al. The performance of two Boeing-GM wheels (GM VII and GMVIII) for the manned lunar rover vehicle. U.S. Army Waterways Experiment Station miscellaneous paper no. M-71-3; 1971 (a).

Green A.J., et al. Performance of Boeing LRV wheels in a lunar soil simulant. Report I, Effect of wheel design and soil. U.S. Army Waterways Experiment Station technical report no. M-71-10; 1971 (b).

GM. Lunar wheel and drive experimental test program, volume 1 -summary technical report, NASA TR67-18; June 1967.

GM. Design and manufacture of wheels for a dual-mode (manned - automatic) Lunar Surface Roving Vehicle. TR70-30 Vol. I; May 1970 (a).

GM. LRV mobility subsystem, critical design review presentation; May 1970 (b).

GM. LRV wheel assembly, technical drawings (\#7552941, 7553028, 7553529, 7553521, 7552939, 7552938, 7552940, 7553027, 7553199); 1971.

Gromov V.V., et al. Lunokhod 2-A retrospective glance after 30 years. Presented at the EGS-AGS EUG Joint Assembly, held in Nice, France, April 6-11; 2003.

Grumman. Design and fabrication of wheels for a lunar surface vehicle, final report. NASA CR102755; June 1970.

Kemurdjian A.L., et al. Planetary rover as an object of the engineering design work. Proceedings of the IEEE International Conference on Robotics \& Automation, Leuven, Belgium; May 1998.

Lockheed. Design, fabrication and delivery of an improved single elastic loop mobility system, volume II, technical report; July 1972. Prepared for NASA under contract no. NAS8-27737.

Mason, et al. Engineering Lunar Model Surface (ELMS), NASA TR-83-D; September 1964.

Markow E.G. Predicted behavior of lunar vehicles with metalastic wheels. SAE paper no. 632J, presented at the Automotive Engineering Congress \& Exposition; January 1963.

Melzer K.J. Performance of Boeing LRV wheels in a lunar soil simulant. Report II, Effect of speed, wheel load and soil. U.S. Army Waterways Experiment Station technical report no. M-71-10; 1971.

NASA. Apollo 14 press kit, release \#71-3K; January 21, 1971.

Northon F.E. Engineer design test of Mobility Test Article model GM-1. U.S. Army Test \& Evaluation Command. NASA CR-102477; Nov 1967.

Pavlics F. Locomotion energy requirements for lunar surface vehicles. Presented at the SAE Automotive Engineering Congress in Detroit, Michigan; January 1966.

Pavlics F., et al. Interview with Ferenc Pavlics, Sam Romano, Don Freidman and Nick DiNapoli, Santa Barbara, CA; January 29, 2007 (a).

Pavlics F., et al. Consultation session with Ferenc Pavlics and Sam Romano, Cleveland, OH; April 3-4, 2007 (b).

Smith, Jr., D.W. Engineer design test of Mobility Test Article, 6×6, block I of NASA lunar surface vehicle studies (hard surface phase). U.S. Army Test \& Evaluation Command. NASA CR-102513; Jan 1967 (revised April 1967).

Vaughan Jr. O.H. Lunar Environment Design Criteria Models for Use in Lunar Surface Mobility Studies, NASA TM-X-53661; September 1967.

Wong J.Y. Terramechanics and off-road vehicles, Elsevier; 1989.

Wong J.Y. Theory of ground vehicles, third edition, John Wiley \& Sons, Inc.; 2001.

Young A. Lunar and Planeter Rovers: The Wheels of Apollo and the Quest for Mars, Praxis Publishing Ltd.; 2007. 
TABLE 1.-OUTLINE OF WIRE MESH AND HOOP SPRING WHEEL DEVELOPMENT PROGRAM (GM 1967)

\begin{tabular}{|c|c|c|c|c|c|c|c|}
\hline \multicolumn{2}{|c|}{ Test articles } & \multicolumn{2}{|c|}{ Initial wheel designs } & \multicolumn{2}{|c|}{ Materials } & \multicolumn{2}{|c|}{ Improved wheel designs } \\
\hline Test type & Mobility & Mechanical & Screening & $\begin{array}{l}\text { Vacuum } \\
\text { welding }\end{array}$ & Mobility & Mechanical & Simulation \\
\hline Description & $\begin{array}{l}\text { - Drawbar-pull } \\
\text { • Wheel } \\
\text { towing } \\
\text { - Steering } \\
\text { resistance }\end{array}$ & $\begin{array}{l}\text { - Load- } \\
\text { deflection } \\
\text { - Dynamic } \\
\text { checkout } \\
\text { - Single } \\
\text { obstacle } \\
\text { - Impact } \\
\text { - Endurance }\end{array}$ & $\begin{array}{l}\text { - Tensile } \\
\text { - Fatigue }\end{array}$ & $\begin{array}{l}\text { - Spring } \\
\text { element } \\
\text { cycling }\end{array}$ & $\begin{array}{l}\text { - Drawbar-pull } \\
\text { - -Wheel } \\
\text { towing }\end{array}$ & $\begin{array}{l}\text { - Load- } \\
\text { deflection } \\
\text { - Dynamic } \\
\text { Checkout } \\
\text { - Single } \\
\text { Obstacle } \\
\text { - Impact } \\
\text { - Endurance }\end{array}$ & $\begin{array}{l}\text { Thermal- } \\
\text { vacuum } \\
\text { Performance } \\
\text { Evaluation }\end{array}$ \\
\hline
\end{tabular}

TABLE 2.-WHEEL REQUIREMENTS TO MEET THE LSSM MISSION ARCHITECTURE (GM 1967)

\begin{tabular}{|l|c|}
\hline \multicolumn{1}{|c|}{ Wheel size } & $101.6 \mathrm{~cm}$ \\
Diameter & $25.4 \mathrm{~cm}$ \\
Width & \\
\hline \multicolumn{1}{|c|}{ Wheel load } \\
Nominal radial & $445 \mathrm{~N}$ \\
Limit radial & $5338 \mathrm{~N}$ \\
Limit lateral & $890 \mathrm{~N}$ \\
\hline \multicolumn{1}{|c|}{ Life } & $100,000 \mathrm{rev}$ \\
\hline
\end{tabular}

TABLE 3.-SUMMARY OF DYNAMOMETER TESTING (GM 1967)

\begin{tabular}{|c|l|c|}
\hline Wheel & \multicolumn{1}{|c|}{ Test mode } & Cycles \\
\hline HOOP-4 & Checkout and calibration & 5,610 \\
& Dynamic ambient & 26,345 \\
& Dynamic thermal-vacuum Total & 24,504 \\
\cline { 2 - 3 } & \multicolumn{1}{|c|}{56,459} \\
\hline \multirow{2}{*}{ MESH-4 } & Checkout and calibration Total & 1,279 \\
& Steady state ambient & 29,685 \\
& Steady state thermal-vacuum & 7,825 \\
& Dynamic thermal-vacuum & 55,376 \\
\cline { 2 - 3 } & \multicolumn{2}{|c|}{94,165} \\
\hline
\end{tabular}




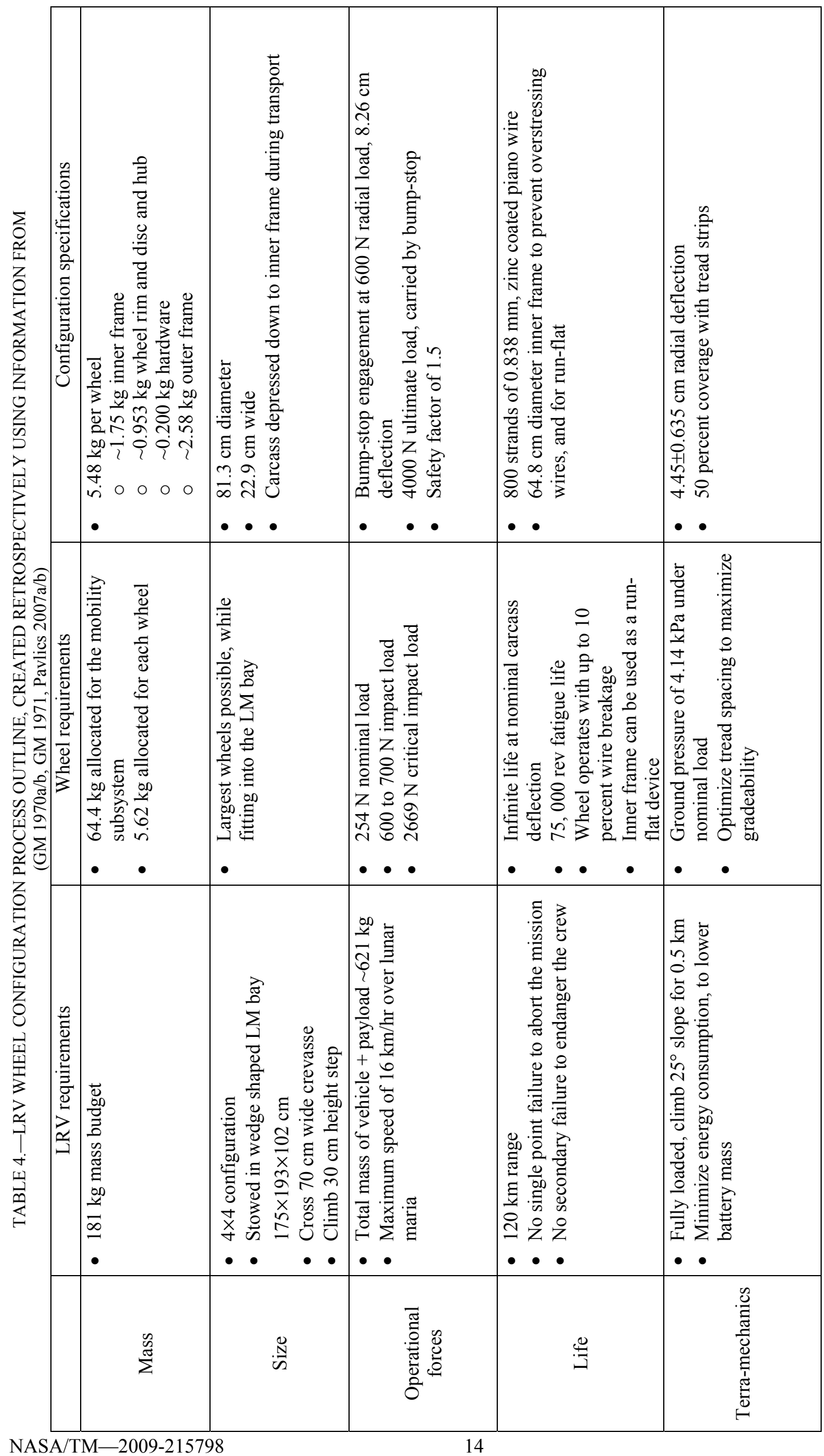


TABLE 5.-RECOMMENDED TERRAIN PARAMETERS

FROM THE LRV RFP (Costes 1972)

\begin{tabular}{|l|l|}
\hline Cohesion & $c_{b}=0$ to $0.035 \mathrm{~N} / \mathrm{cm}^{2}$ \\
Internal friction angle & $\varphi_{b}=35 \pm 4^{\circ}$ \\
Slip coefficient & $K=1.78 \pm 0.76 \mathrm{~cm}$ \\
Exponent of deformation & $n=1$ dimensionless) \\
Cohesive modulus of deformation & $k_{c}=0$ to $0.28 \mathrm{~N} / \mathrm{cm}^{\mathrm{n}+1}$ \\
Frictional modulus of deformation & $k_{\varphi}=0.82 \mathrm{~N} / \mathrm{cm}^{\mathrm{n}+2}$ \\
\hline
\end{tabular}

TABLE 6.-VISUALLY ESTIMATED AVERAGE WHEEL PERFORMANCE DATA ORIGINALLY USED TO SELECT THE LRV WHEEL TREAD COVERAGE (Freitag 1972). TERRAIN CONDITION LSS1 IS SHOWN, BUT DATA FOR ALL TERRAIN CONDITIONS ARE REPORTED IN (Green 1971b)

\begin{tabular}{|c|l|c|c|c|}
\hline \multicolumn{1}{|c|}{ Terrain } & \multicolumn{1}{|c|}{ Wheel coverage } & No. tests & $\begin{array}{c}\text { Power no. }{ }^{{ }^{a}} \\
\text { (at zero pull) }\end{array}$ & $\begin{array}{c}\text { Pull coeff. }^{\text {b }} \\
\text { (at 20 percent slip) }\end{array}$ \\
\hline \multirow{3}{*}{ LSS1 } & None & 4 & 0.12 & 0.22 \\
& 50 percent with chevron tread-strips & 6 & 0.08 & 0.33 \\
& 75 percent with chevron tread-strips & 4 & 0.19 & 0.21 \\
& 100 percent with rubber & 2 & 0.18 & 0.02 \\
& 100 percent with rubber and aggressive grousers & 4 & 0.18 & 0.11 \\
\hline
\end{tabular}

${ }^{a}$ Power number is defined as the energy consumed per unit of distance, per unit of weight

${ }^{b}$ Pull coefficient is defined as the drawbar pull normalized to the weight

TABLE 7.-STATISTICAL SUMMARY OF THE EXPERIMENTAL WHEEL SLIP (PERCENT) REQUIRED TO CLIMB A $25^{\circ}$ SLOPE ON LSS1-LSS4.

[This information was extracted from the data shown in Figure 13.]

\begin{tabular}{|c|c|c|c|}
\hline $\begin{array}{c}\text { Average case } \\
\text { percent }\end{array}$ & $\begin{array}{c}\text { Average } \sigma^{\mathrm{a}} \\
\text { percent }\end{array}$ & $\begin{array}{c}\text { Average } 2 \sigma^{\mathrm{a}} \\
\text { percent }\end{array}$ & $\begin{array}{c}\text { Average } 3 \sigma^{\mathrm{a}} \\
\text { percent }\end{array}$ \\
\hline 59.5 & 72.0 & 79.5 & 84.5 \\
\hline
\end{tabular}

${ }^{\mathrm{a}} \sigma$ (sigma) refers to the standard deviation of the wheel performance data for slip versus slope-climbing capability. 


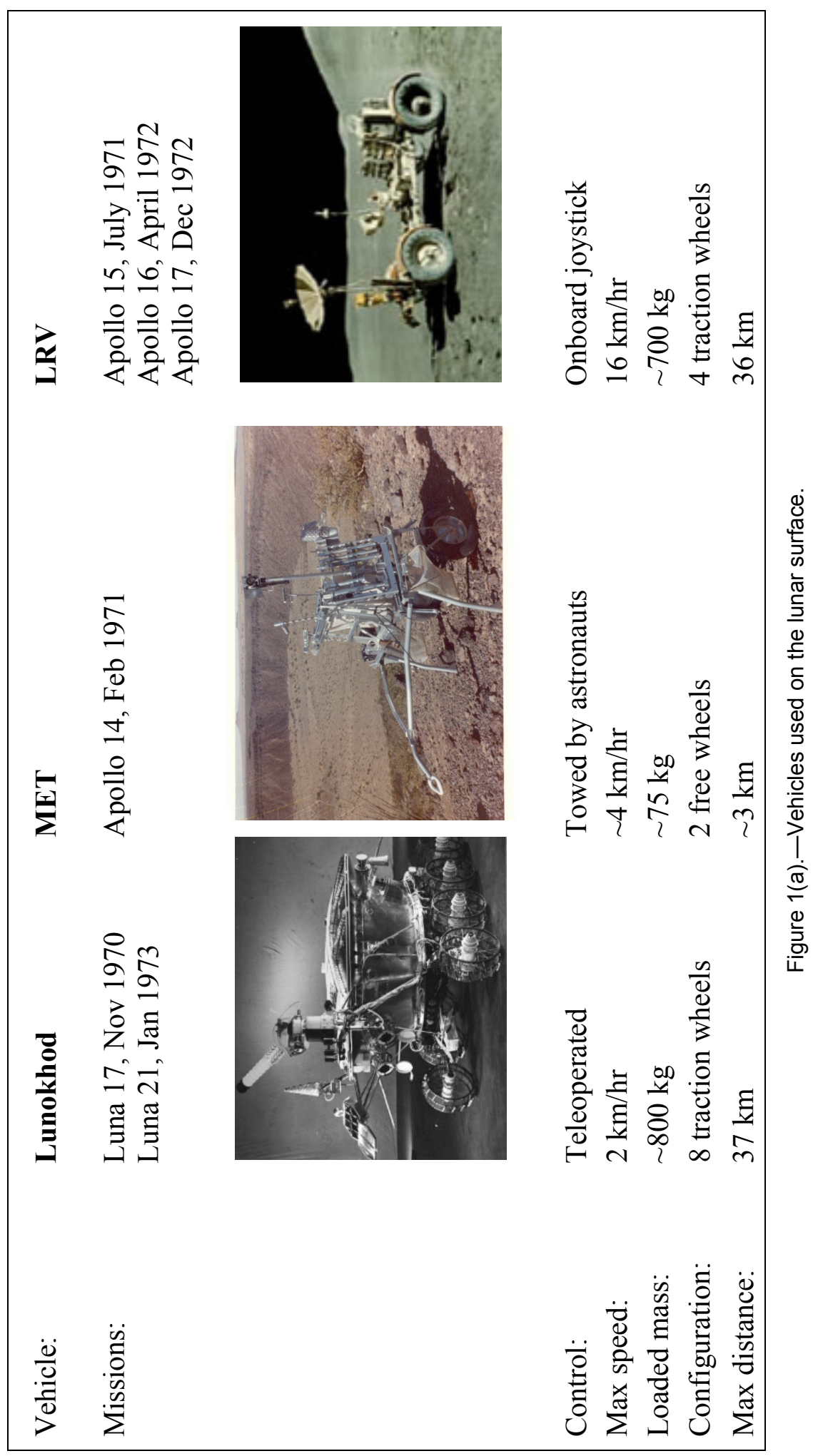




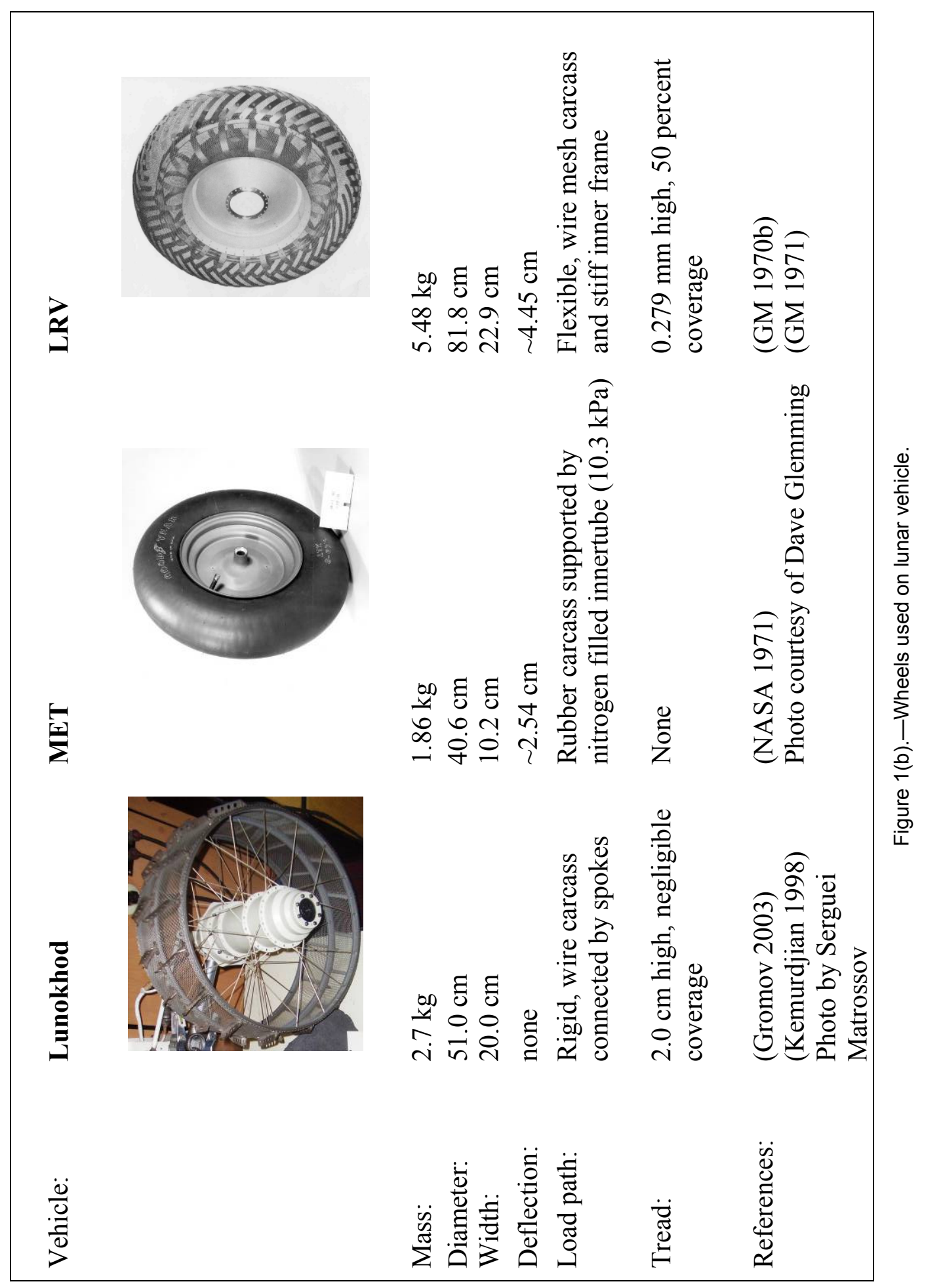




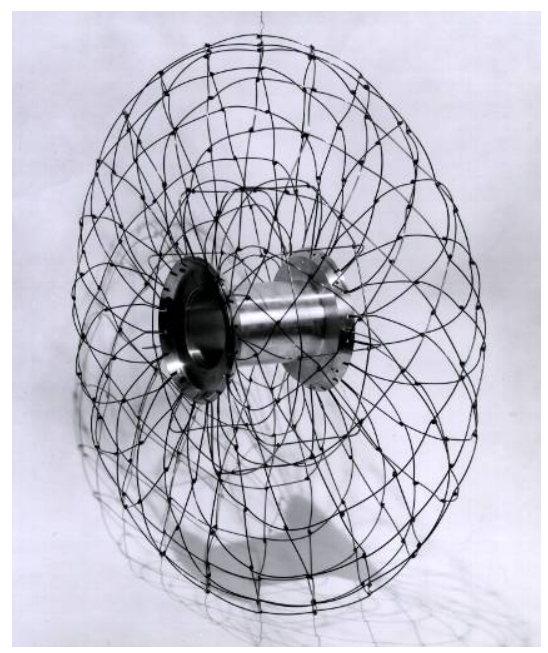

(a) Wire frame wheel

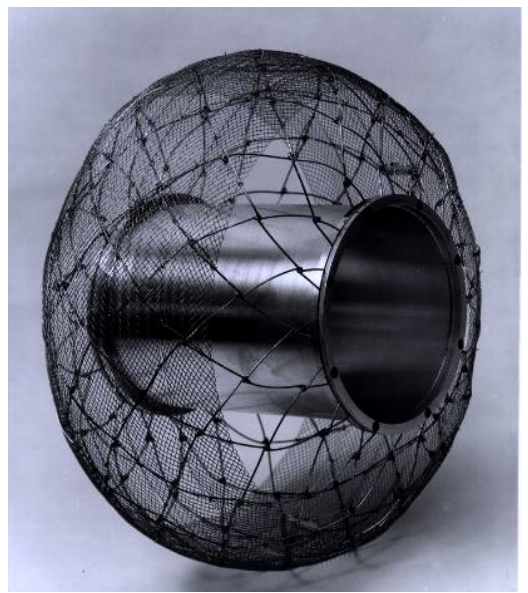

(c) With partial mesh cover

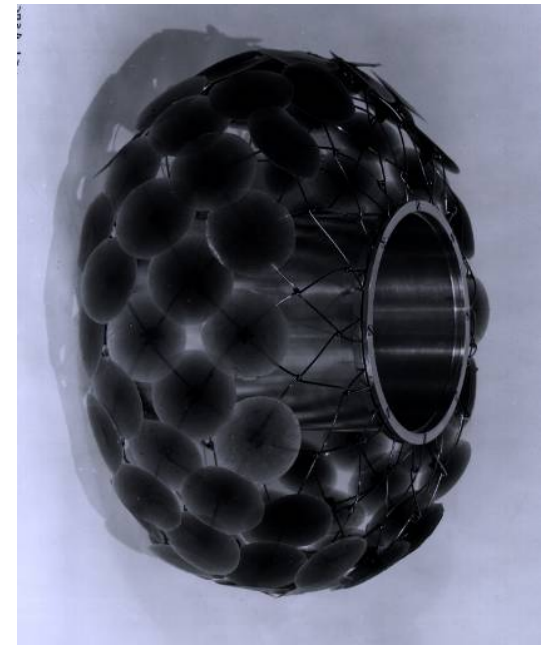

(b) With traction pads

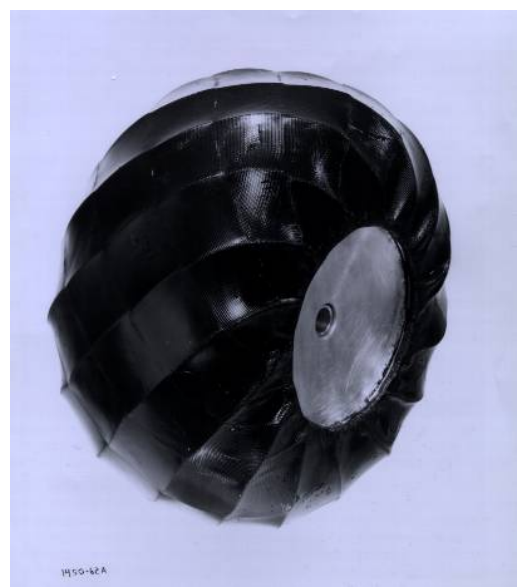

(d) With full fabric cover

Figure 2.--Prototype wheels made by GM, DRL, and Goodyear for SLRV. Courtesy of Dave Glemming. 


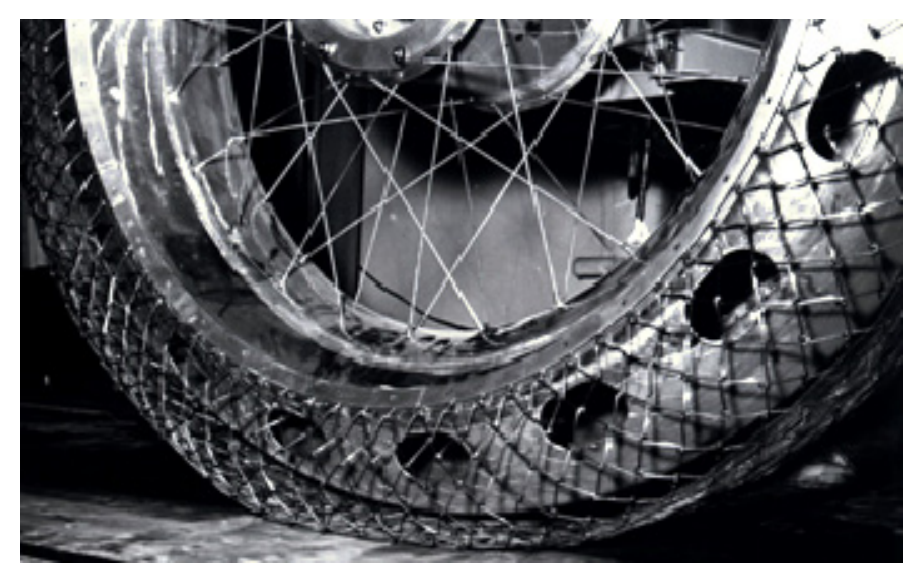

Figure 3.-Prototype wheel developed for MOLAB by GM, DRL, and Goodyear. Courtesy of Dave Glemming.

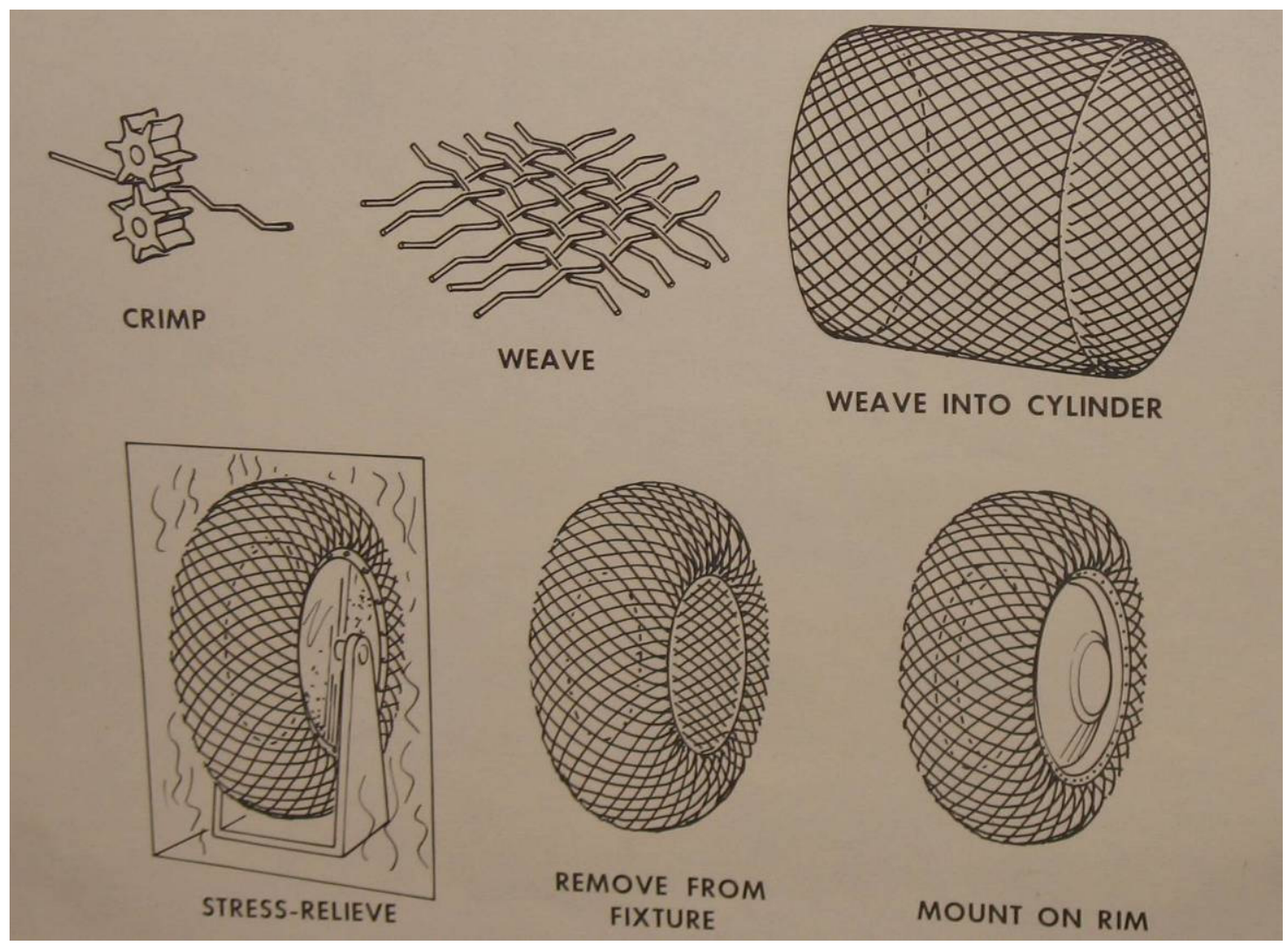

Figure 4.-Cartoon showing wire mesh carcass manufacturing processes. Courtesy of Don Freidman. 


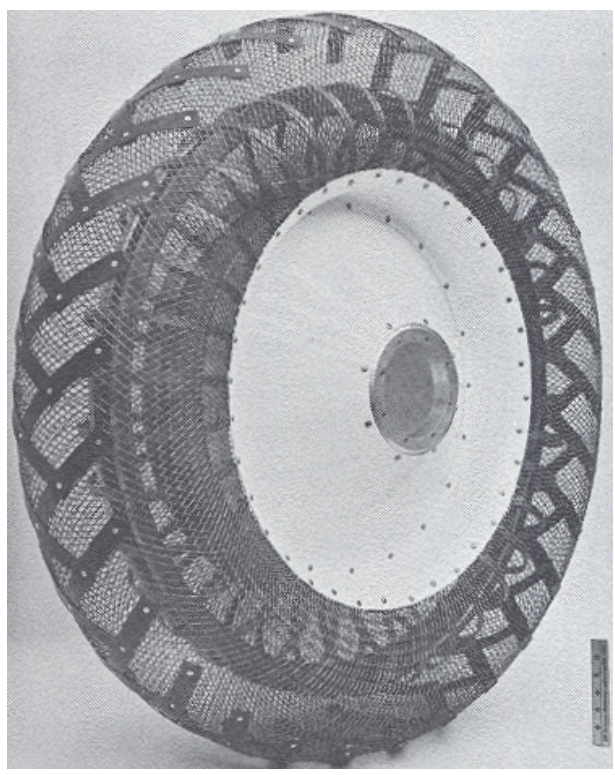

Figure 5.-Prototype wire mesh wheel by GM DRL.



Figure 6.-Various small scale lunar vehicles with articulated frames and unconventional running gear (Bekker 1962, Bekker 1963). The vehicle on the left has high width to diameter wheel ratio, the middle vehicle uses screw propulsion, and the right vehicle has spaced link tracks. Courtesy of Don Freidman. 


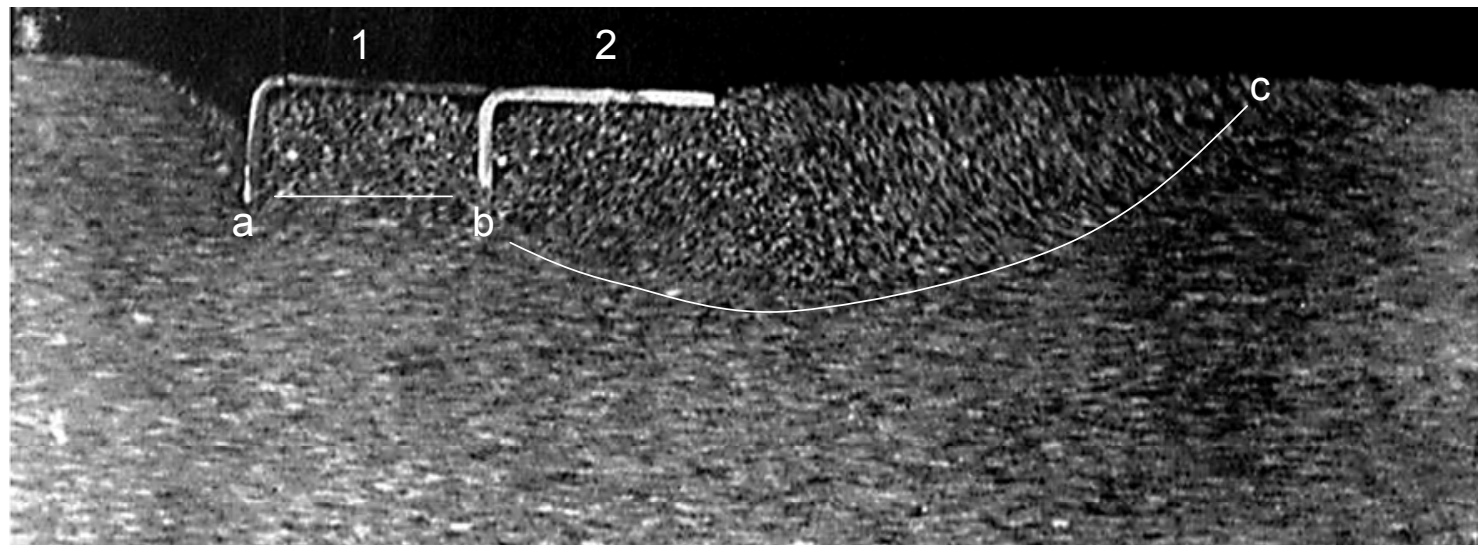

Figure 7.-Extended exposure photograph showing the action of soil underneath adjacent and spaced cleats. Local failure occurred along surface $a$ to $b$ and general failure occurred along surface $b$ to $c$. Original work performed by Dr. M.G. Bekker (Bekker 1960). Courtesy of Ferenc Pavlics. 


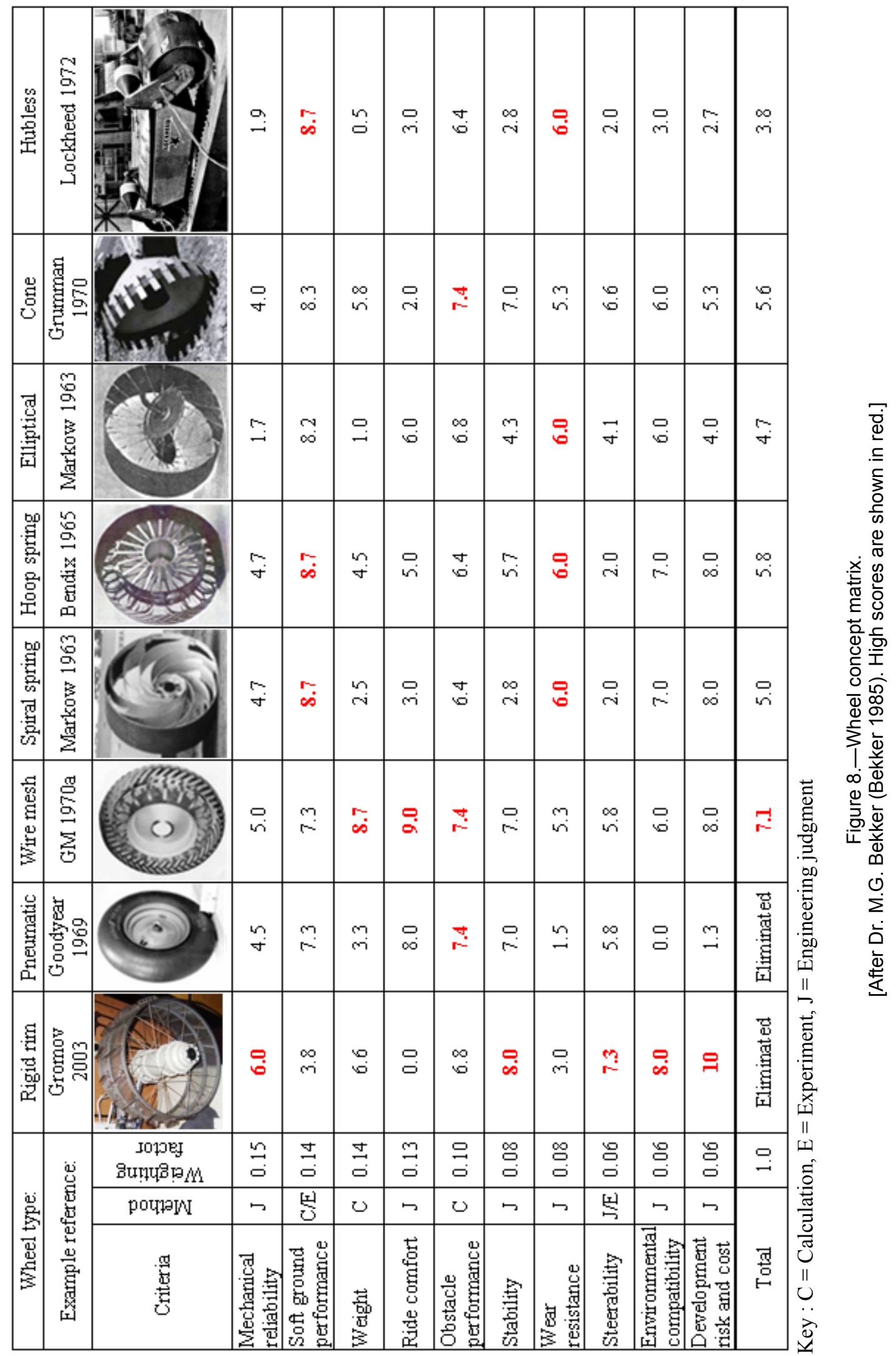



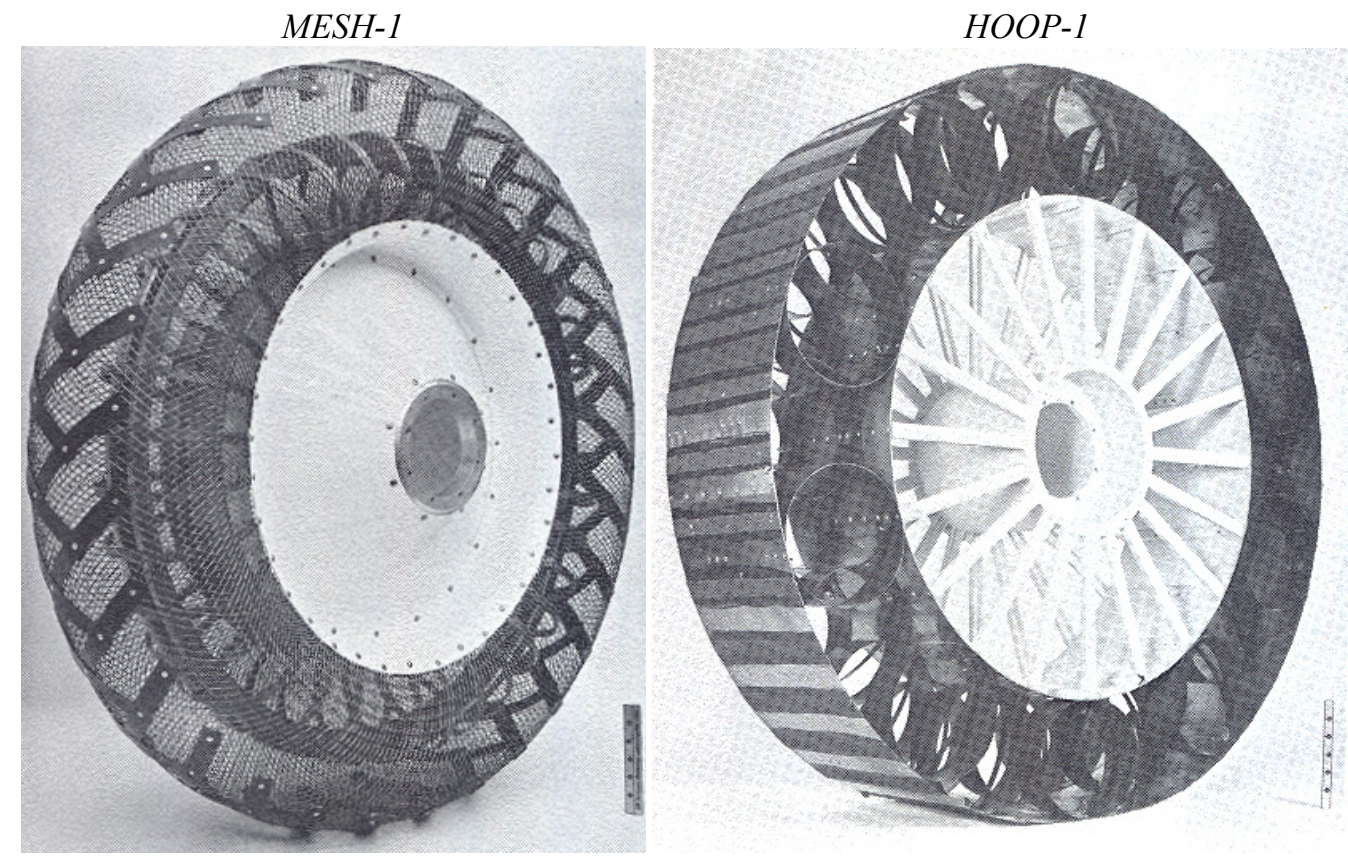

Figure 9.-Initial $101.6 \mathrm{~cm}$ diameter wire mesh (left side) and hoop spring (right side) wheels (GM 1967).



Figure 10.-Wheel dynamometer for mission simulation inside of a thermalvacuum chamber (GM 1967). 


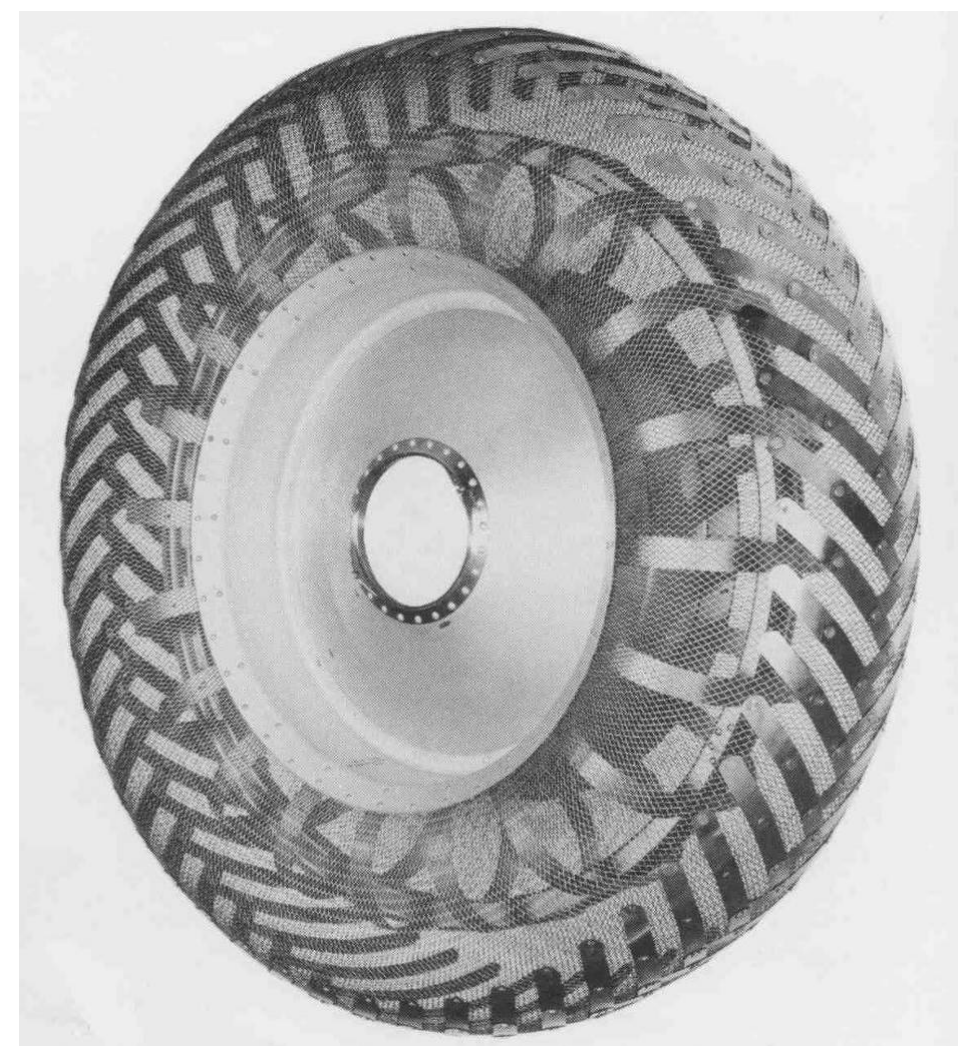

Figure 11.-Final LRV wheel.

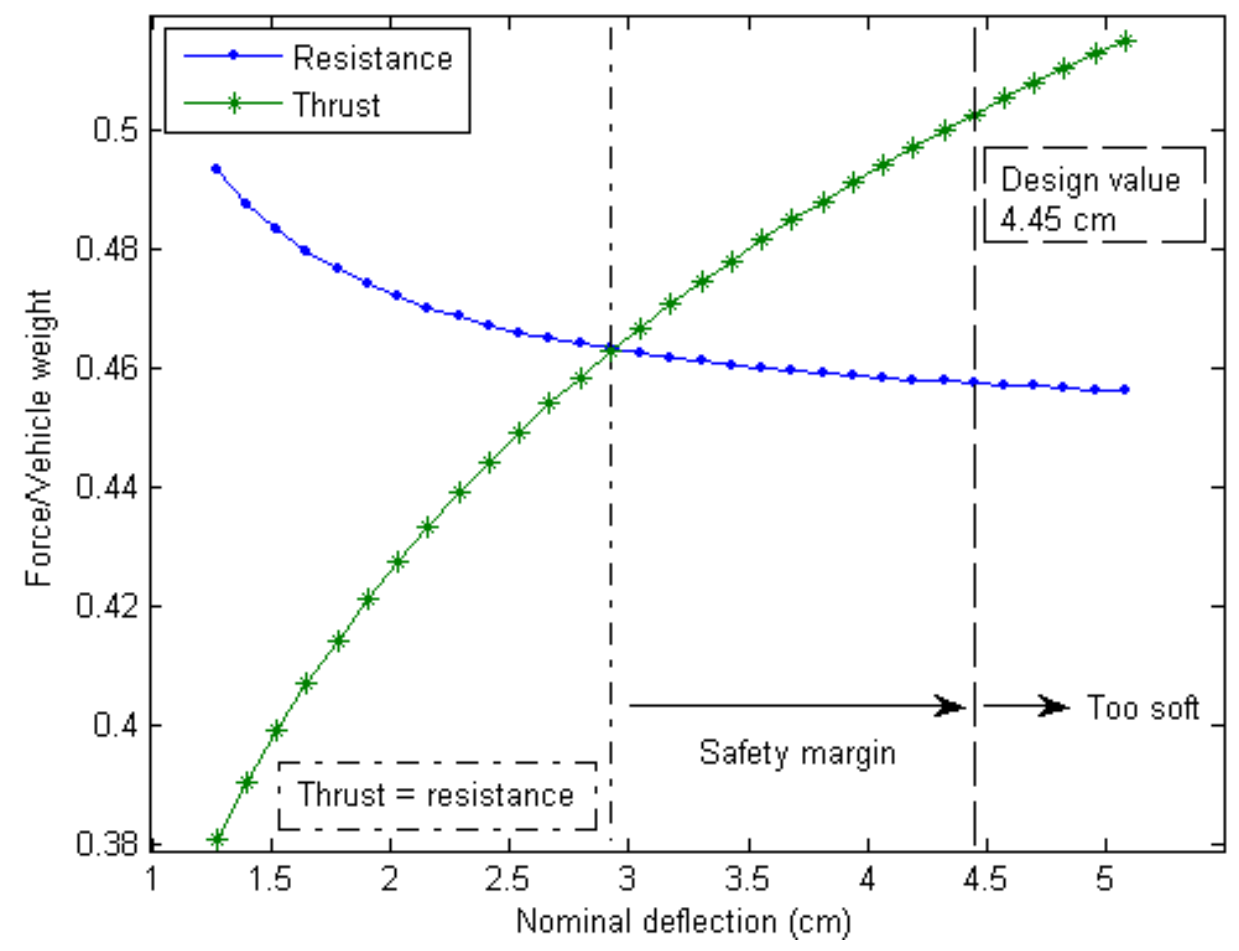

Figure 12.-Calculated LRV mobility forces at 20 percent slip on a $25^{\circ}$ slope. Mobility is achieved when thrust exceeds motion resistance (terrain resistance + internal loss + gravitational resistance). 


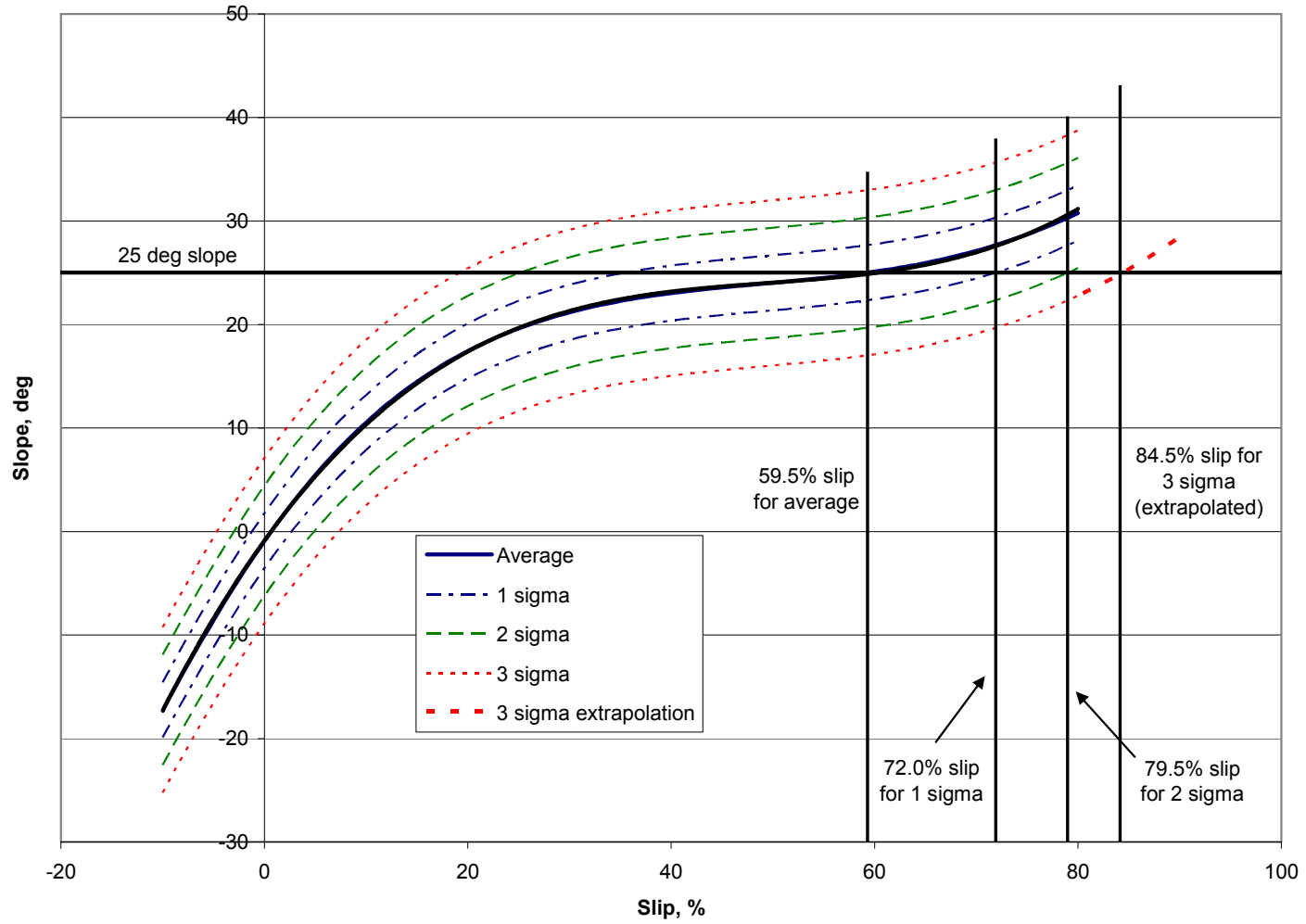

Figure 13.-LRV climbing performance in loose, air-dry lunar soil simulant (LSS1, LSS2, LSS3, and LSS4). Climbing performance was predicted based on single-wheel tests using the correlation method proposed by Freitag (Freitag 1970/1972). The mean trend was generated by curve-fitting the first and second pass data (simulating front and rear tires) separately using 3rd degree polynomials, then taking the average of the two curves. The upper and lower ranges are represented as various multiples of the standard deviation (sigma), which was determined using General Uncertainty Analysis (Coleman 1989). 


\begin{tabular}{|c|c|c|}
\hline \multicolumn{2}{|c|}{ REPORT DOCUMENTATION PAGE } & $\begin{array}{l}\text { Form Approved } \\
\text { OMB No. 0704-0188 }\end{array}$ \\
\hline \multicolumn{3}{|c|}{ 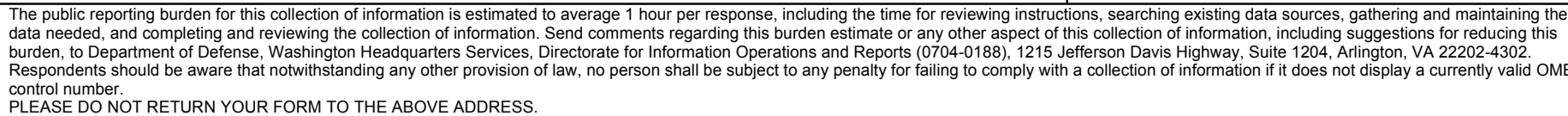 } \\
\hline $\begin{array}{l}\text { 1. REPORT DATE (DD-MM-YYYY) } \\
01-12-2009\end{array}$ & $\begin{array}{l}\text { 2. REPORT TYPE } \\
\text { Technical Memorandum }\end{array}$ & 3. DATES COVERED (From - To) \\
\hline \multirow{3}{*}{\multicolumn{2}{|c|}{$\begin{array}{l}\text { 4. TITLE AND SUBTITLE } \\
\text { The Development of Wheels for the Lunar Roving Vehicle }\end{array}$}} & 5a. CONTRACT NUMBER \\
\hline & & 5b. GRANT NUMBER \\
\hline & & 5c. PROGRAM ELEMENT NUMBER \\
\hline \multirow{3}{*}{\multicolumn{2}{|c|}{$\begin{array}{l}\text { 6. AUTHOR(S) } \\
\text { Asnani, Vivake; Delap, Damon; Creager, Colin }\end{array}$}} & 5d. PROJECT NUMBER \\
\hline & & 5e. TASK NUMBER \\
\hline & & $\begin{array}{l}\text { 5f. WORK UNIT NUMBER } \\
\text { WBS } 140765.04 .02 .01 .02 .03\end{array}$ \\
\hline \multicolumn{2}{|c|}{$\begin{array}{l}\text { 7. PERFORMING ORGANIZATION NAME(S) AND ADDRESS(ES) } \\
\text { National Aeronautics and Space Administration } \\
\text { John H. Glenn Research Center at Lewis Field } \\
\text { Cleveland, Ohio 44135-3191 }\end{array}$} & $\begin{array}{l}\text { 8. PERFORMING ORGANIZATION } \\
\text { REPORT NUMBER } \\
\text { E-17060 }\end{array}$ \\
\hline \multirow{2}{*}{\multicolumn{2}{|c|}{$\begin{array}{l}\text { 9. SPONSORING/MONITORING AGENCY NAME(S) AND ADDRESS(ES) } \\
\text { National Aeronautics and Space Administration } \\
\text { Washington, DC 20546-0001 }\end{array}$}} & $\begin{array}{l}\text { 10. SPONSORING/MONITOR'S } \\
\text { ACRONYM(S) } \\
\text { NASA }\end{array}$ \\
\hline & & $\begin{array}{l}\text { 11. SPONSORING/MONITORING } \\
\text { REPORT NUMBER } \\
\text { NASA/TM-2009-215798 }\end{array}$ \\
\hline \multicolumn{3}{|c|}{$\begin{array}{l}\text { 12. DISTRIBUTION/AVAILABILITY STATEMENT } \\
\text { Unclassified-Unlimited } \\
\text { Subject Category: } 37 \\
\text { Available electronically at http://gltrs.grc.nasa.gov } \\
\text { This publication is available from the NASA Center for AeroSpace Information, 443-757-5802 }\end{array}$} \\
\hline
\end{tabular}

\section{SUPPLEMENTARY NOTES}

\section{ABSTRACT}

The Lunar Roving Vehicle (LRV) was developed for NASA's Apollo program so astronauts could cover a greater range on the lunar surface, carry more science instruments, and return more soil and rock samples than by foot. Because of the unique lunar environment, the creation of flexible wheels was the most challenging and time consuming aspect of the LRV development. Wheels developed for previous lunar systems were not sufficient for use with this manned vehicle; therefore, several new designs were created and tested. Based on criteria set by NASA, the choices were narrowed down to two: the wire mesh wheel developed by General Motors (GM), and the hoop spring wheel developed by the Bendix Corporation. Each of these underwent intensive mechanical, material, and terramechanical analyses, and in the end, the wire mesh wheel was chosen for the LRV. Though the wire mesh wheel was determined to be the best choice for its particular application, it may be insufficient towards achieving the objectives of future lunar missions that could require higher tractive capability, increased weight capacity, or extended life. Therefore lessons learned from the original LRV wheel development and suggestions for future Moon wheel projects are offered.

\section{SUBJECT TERMS}

Lunar roving vehicles; Wheels; Moon; Lunar exploration; Lunar surface; Manned lunar surface vehicles; General Motors

\begin{tabular}{|c|c|c|c|c|c|}
\hline \multicolumn{3}{|c|}{ 16. SECURITY CLASSIFICATION OF: } & \multirow{2}{*}{$\begin{array}{l}\text { 17. LIMITATION OF } \\
\text { ABSTRACT } \\
\text { UU }\end{array}$} & \multirow{2}{*}{$\begin{array}{l}\text { 18. NUMBER } \\
\text { OF } \\
\text { PAGES } \\
31\end{array}$} & \multirow{2}{*}{$\begin{array}{l}\text { 19a. NAME OF RESPONSIBLE PERSON } \\
\text { STI Help Desk (email:help@ } \text { sti.nasa.gov) } \\
\text { 19b. TELEPHONE NUMBER (include area code) } \\
\text { 443-757-5802 }\end{array}$} \\
\hline $\begin{array}{l}\text { a. REPORT } \\
U\end{array}$ & $\begin{array}{l}\text { b. ABSTRACT } \\
U\end{array}$ & $\begin{array}{l}\text { c. THIS } \\
\text { PAGE } \\
\text { U }\end{array}$ & & & \\
\hline
\end{tabular}



